\title{
Tolerancia, verdad y libertad de conciencia en el siglo XVIII *
}

\author{
EDUARDO BELLO
}

Universidad de Murcia

RESUMEN. La defensa de la tolerancia, en el siglo XVIII, se apoya en dos líneas de argumentación, que observamos en pensadores como Montesquieu y Rousseau, Diderot, Romilly y Voltaire. Una es la que deconstruye el concepto de verdad absoluta aplicado tanto a la doctrina (ortodoxa, por ello) revelada por Dios como a la institución considerada única depositaria de tal verdad, la Iglesia católica, única «verdadera». Otra sigue este argumento: si se reconocen los derechos de la conciencia a toda confesión religiosa, ¿acaso podría evitarse una justificación circular de la intolerancia? Sin renunciar a los derechos de la conciencia, base de las libertades individuales, Romilly y Voltaire sostienen la separación Iglesia-Estado, como lo hiciera Locke, asignando a éste el ius circa sacra. Sólo sobre esta base se logra fundamentar la idea y la práctica de la tolerancia no sólo religiosa, sino también universal o multicultural.
ABSTRACT. The XVIII century defence of tolerance rests upon two lines of argument; lines that we can observe in thinkers such as Montesquieu and Rousseau, Diderot, Romilly and Voltaire. The first deconstructs the concept of absolute truth as it applies not only to the (orthodox) doctrine itself, as revealed by God, but also to the Catholic Church insofar as it is taken to be the only institution where truth resides uniquely. The second line of argument would run as follows: Once we acknowledge the rights of consciousness to every single religion, how can we possibly avoid a circular justification of intolerance? Romilly and Voltaire defend, without renouncing to the rights of consciousness (which are the base of individual liberties), the Lockean thesis of the separation Church-State. However, they assign to the State the ius circa sacra. It is only upon this foundation that the idea and the practice of tolerance, both religiously as well as universally and multiculturally speaking, can be constructed.

\footnotetext{
* Este trabajo, que se enmarca en el proyecto de investigación BFF2002-02315, procede del texto presentado en el I Congreso de la Sociedad Académica de Filosofía, en Valencia, del 6 al 8 de febrero de 2003.
} 
A pesar de las diferencias históricas y contextuales, el problema de la tolerancia en el siglo XVIII remite originariamente a la siguiente pregunta: ipor qué una religión que predica el amor, la igualdad y la fraternidad se ha hecho intolerante? Esta pregunta, que ya se había hecho Spinoza y sobre la que escriben Bayle y Locke a finales del siglo XVII, la repite Diderot en el artículo «Intolérance» de la Encyclopédie casi en la misma fecha en la que Voltaire publica su Tratado sobre la Tolerancia (1763). Ciertamente, la religión no es la única dimensión de la existencia humana en la que está en juego la tolerancia o la intolerancia; pero en el Siglo de las Luces fue, quizá, el síntoma más expresivo del problema. Presentar las conexiones entre los tres problemas señalados en el título -el problema de la tolerancia, el de la Iglesia «verdadera» y el de la libertad de conciencia - constituye el objeto de este trabajo.

El problema de la verdad aquí planteado no refiere, pues, a la pregunta por la verdad desde un punto de vista teórico o epistemológico en sentido estricto ${ }^{~}$. El marco de la pregunta por la verdad no es sino el definido por los otros dos conceptos - el de la tolerancia y el de la libertad de conciencia- que, en el siglo XVIII como en los dos anteriores, forman parte de la controversia religiosa con notable implicación política ${ }^{2}$. Locke, por ejemplo, comienza su célebre Carta sobre la Tolerancia (1689) afirmando que «la tolerancia es la característica principal de la Iglesia verdadera» ${ }^{3}$. Y en las páginas que siguen aparecen con frecuencia expresiones como la «verdadera» religión, el «verdadero» cristiano, la creencia «verdadera». Ahora bien, ¿cuál es la solución de Locke a la pregunta por la verdadera Iglesia, la verdadera creencia, la religión verdadera? En su respuesta, el autor de la Carta comienza distinguiendo las respectivas funciones de la razón y de la fe, para llegar a la conclusión de que, en realidad, no existe una sino una pluralidad de Iglesias verdaderas. En efecto, considera Locke que la razón tiene a la vez una función distinta y complementaria de la fe. Tienen funcio-

\footnotetext{
${ }^{1}$ Si tuviera que hacer explícitos los referentes epistemológicos, tendría que desarrollar la posición relevante de la razón en Descartes frente al argumento de autoridad, la afirmación de la experiencia en Locke frente al innatismo cartesiano y, finalmente, la tesis de la crítica histórica en Bayle frente a la tradición.

2 Cf. L. Madanes, «Tolerancia, prudencia y búsqueda de la verdad», en M. Cruz (comp.), Tolerancia o barbarie, Barcelona, Gedisa, 1998, pp. 13-50; Madanes centra su análisis en el caso Galileo y la teoría de Hobbes. S. Giner, «Verdad, tolerancia y virtud republicana», ibid., pp. 119139; observa Giner que la relación entre «la delicada relación entre verdad y tolerancia» ha sido poco estudiada. G. Saupin, R. Fabre y M. Launay (dirs.), La Tolérance, Colloque international de Nantes (mayo de 1998), Rennes, Presses Universitaires de Rennes, 1999. M. Firpo, Il problema della tolleranza religiosa, Turín, Loescher Editore, 1989. J. Leclerc, Histoire de la tolérance au siècle de la Réforme, París, Editions Montaigne, 1955 (reed. A. Michel, 1994).

3 J. Locke, «A Letter concerning Toleration», en Thomas Ted et al. (eds.), The Works of John Locke, Londres, 1923 (reed. en Darmstadt, 1963) [P. Bravo (ed.), Carta sobre la Tolerancia, Madrid, Tecnos, 1985, p. 3]. Cf. J. Hortun y S. Mendus (eds.), A Letter concerning Toleration in focus, Londres, Routledge, 1991.
} 
nes distintas, porque mientras la razón produce «conocimiento» (knowledge) de un enunciado verdadero o probable, la fe sólo consiste en la adhesión o «asentimiento» (assent) al sentido de un enunciado cuyo valor de verdad depende de la aceptación o no del hecho de la revelación y de sus intérpretes. Pero desempeñan, además, funciones complementarias, porque - según Locke - «la apelación a la fe dejando de lado toda verificación o control racional ha sido la causa de los excesos fanáticos», acríticos e intolerantes ${ }^{4}$. De ahí la necesidad de afirmar el papel de la razón, incluso en aquellas materias que le exceden, propias de la revelación. Y si el resultado de verificar la autenticidad de la revelación conduce a reducir las verdades de la fe a una sola, a saber, la divinidad de Cristo, la consecuencia lógica, según Locke, es que ya no se puede identificar «religión verdadera» con «Iglesia verdadera». La religión verdadera será, en adelante, la que asuma esa sencilla verdad: Jesús es el Mesías; mientras que Iglesia verdadera es toda aquella que, además de aceptar esa verdad fundamental, posee algunos rasgos distintivos que no deben entrar en contradicción con lo que hay que entender por religión verdadera. Por lo tanto, Locke no sólo admite una pluralidad de Iglesias verdaderas, sino que pone al descubierto la falsedad de quien identifica la verdadera religión con una determinada Iglesia. De ahí su crítica a J. Proast, quien identifica la verdadera religión con la Iglesia anglicana ${ }^{5}$, así como según ésta los papistas identifican la verdadera religión con la Iglesia católica.

\section{De la verdad absoluta a la intolerancia religiosa}

Pues bien, esta línea de argumentación sobre la verdad, cuando se trata del problema de la tolerancia de creencias, credos u opiniones distintas, o de hacer compatibles en la práctica verdades contrapuestas, se observa en el siglo XVIII en los textos que defienden la tolerancia, como la Encyclopédie y el Tratado sobre la Tolerancia de Voltaire. En el primero, concretamente en el artículo «Intolérance», observamos que Diderot pone al descubierto el mecanismo de la intolerancia religiosa, que no es sino el resultado de considerar verdadera sólo la religión propia, frente a la cual son falsas todas las demás y, por lo tanto, susceptibles de ser perseguidas. «La intolerancia eclesiástica - escribe - consiste en considerar falsa toda religión distinta de la que uno profesa, y en demostrarlo sin detenerse ante ningún terror, por ningún respeto humano» ${ }^{6}$. Pero defender como verdadera sólo la religión que

\footnotetext{
4 J. I. Solar Cayón, La teoría de la tolerancia en John Locke, Madrid, Dykinson, 1996, p. 237.

5 J. Locke, en Thomas Ted et al. (eds.), The Works of John Locke, op. cit., vol. III, p. 156 (Ensayo sobre el entendimiento humano, Madrid, Editora Nacional, Lib. IV, cap. XIX, sec. 14

6 D. Diderot (1765), art. «Intolérance», en Diderot et d'Alembert, Encyclopédie, Parma, F. M. Ricci Editore, vol. 15, I, 71.
} 1980). 
uno profesa, y considerar falsas todas las demás, no sólo genera un círculo vicioso, sino también el círculo de la violencia y el terror, es decir, las guerras de religión. Tal vez pensando en ellas comenta Diderot: «Si vuestra verdad me proscribe, mi error que yo tomo por la verdad, os proscribirá. [...] En estos últimos tiempos el apologista de la revocación del Edicto de Nantes ha sido considerado un hombre sangriento, con el cual no era necesario compartir el mismo techo. ¿Cuál es la vía de la humanidad? ¿La del perseguidor que golpea, o la del perseguido que se queja?»?

En términos similares se había pronunciado Montesquieu en El espíritu de las Leyes, poniendo en boca de un judío la «Humilde exhortación a los inquisidores de España y Portugal», después de que una judía de dieciocho años hubiera sido quemada en Lisboa en un auto de fe. Entre otras reflexiones hace la siguiente: «Pues si poseéis esta verdad (la verdad revelada), no nos la ocultéis por la manera en que nos la proponéis. El carácter de la verdad reside en su triunfo sobre los corazones y los espíritus, y no en esta incapacidad que confesáis cuando os valéis de los suplicios para obligar a aceptarla» ${ }^{8}$. Como sostiene el autor del artículo «Tolérance», Romilly, «la verdad produce herejes como el sol impurezas» (t 45). ¿Por qué la verdad produce herejes? Porque se define previamente un cuerpo de doctrina, a la que se califica de verdadera, sobre una triple base: la sagrada Escritura, una determinada tradición y una sola interpretación: la de la Iglesia católica. Se afirma luego el principio de identidad o de uniformidad, mediante el calificativo «ortodoxa»; de modo que, frente a ésta, todo otra doctrina es «heterodoxa». Más aún: la doctrina ortodoxa, puesto que es la única verdadera, es universalizable. Si tal es la única doctrina verdadera, todos tienen que adherirse a ella como única vía de salvación: «sólo dentro de la Iglesia hay salvación», reza el lema que ha guiado durante siglos tanto al teólogo como al párroco, tanto al predicador como al misionero, pero también al inquisidor, al perseguidor y al torturador. En consecuencia, todo el que se desvíe de la doctrina ortodoxa es un «hereje». La herejía no es sino la tesis en desacuerdo con la doctrina ortodoxa, la única verdadera, definida por la Iglesia católica, esto es, universal. Basta evocar las 95 tesis que Lutero fijó en la puerta de la iglesia de Wittenberg. El hereje, según Bossuet, no es poseedor de la verdad, sino sólo de una opinión, que es falsa verdad o error; por lo tanto, condenable, porque tal opinión se aleja de la verdadera opinión definida como doctrina verdadera. Más aún: si disentir de la verdadera fe es destruir la unidad de creencia, esto es, corromperla o falsificarla, el falsificador de la fe comete un delito mayor que el falsificador de moneda. No otro es el argumento de la Iglesia católica, formulado por Tomás de Aquino: «Es mucho más grave corromper la fe que asegura la vida del alma que falsificar la

\footnotetext{
7 Ibid., I, 72.

${ }^{8}$ Montesquieu, El espíritu de las Leyes, edición de E. Tierno Galván, Madrid, Tecnos, 1980 , Lib. XXV, cap. XIII, p. 365.
} 
moneda que sólo sirve para la vida temporal. Por lo tanto, si los falsificadores de moneda [...] son inmediatamente condenados a muerte en buena justicia [...], con mucha mayor razón los herejes, una vez convencidos de herejía, pueden ser no sólo excomulgados sino condenados a muerte con justicia» ${ }^{9}$. Ciertamente, la verdad produce herejes - quienes se atrreven a disentir de la verdad ortodoxa-, y algo más. Produce también persecuciones e instituciones (la Inquisición, por ejemplo) destinadas a perseguir, torturar y eliminar a los así denominados herejes.

\section{La libertad de conciencia, base de la tolerancia}

Contra las prácticas y formas de intolerancia, contra el hecho mismo del fanatismo intolerante producido por la defensa de una sola verdad, se alzan las voces defensoras de la tolerancia del siglo XVm, como las de Montesquieu y Diderot, las de Rousseau y Voltaire, o las de Romilly en el artículo «Tolérance» ${ }^{10}$. La tesis de este último es la afirmación insistente del pluralismo frente a la defensa de la uniformidad, es la consideración de que la opinión del disidente reconocida por Bossuet, lejos de ser condenable, ha de ser elevada al rango de una posible verdad. De otro modo, para Romilly, «la diversidad de opiniones reinará siempre entre los seres humanos por muy imperfectos que sean». ¿Cuál es su argumento? Aduce al menos tres razones en favor de su tesis. En primer lugar, saliendo al paso de la objeción que opone los inconvenientes de la multiplicidad de religiones a las ventajas de la uniformidad de creencia en un Estado, remite al autor de El espíritu de las Leyes, quien se pregunta si, a la hora de organizar el Estado, «la grandeza del genio no consiste sino en saber en qué casos (policía, comercio, leyes, religión) es necesaria la uniformidad y en cuáles las diferencias son necesarias». En segundo lugar, si la pregunta de Montesquieu no tiene una sola respuesta - la de la uniformidad-, sino que abre la vía a la pluralidad, a favor de ésta aduce Romilly un nuevo argumento, a saber, que «la historia del espíritu humano es una prueba continua» de la multiplicidad de opiniones y creencias, porque «la diversidad de sentimientos siempre subsistirá entre los hombres». Como cabe observar, el argumento histórico es ampliado por Voltaire en Ensayo sobre las costumbres y el espíritu de las naciones, sobre todo en la Introducción redactada en 1765 con el título Philosophie de l'his-

\footnotetext{
${ }_{9}$ Sum. Th., II, II, q. 11, art. 3. Cf. P. Tierry, La Tolérance, París, Puf, 1997, p. 17.

10 Jean-Edme Romilly, pastor ginebrino e hijo del enciclopedista Jean Romilly, redacta este artículo para el tomo XVI de la Enciclopédie, cuya publicación, junto con los tomos VIII-XVII, se reanuda en 1765 , después de siete años de prohibición. La redacción del artículo (entre 1762 y 1764) coincide con el caso Jean Calas (1762-1765), el Tratado de la tolerancia (1763) de Voltaire, la persecución de Rousseau (desde 1762) y la expulsión de los jesuitas de Francia (1764); algunas semanas después de la aparición del tomo XVI, a comienzos de 1766, el caballero de la Barre fue decapitado a la edad de diecinueve años.
} 
toire. Finalmente -y no por ser anotado en tercer lugar es el de menor peso-, Romilly aduce un argumento decisivo a favor de la tesis de la pluralidad: los derechos inviolables de la conciencia. «Dios nunca ha ordenado que los pueblos sometan su conciencia al parecer de sus monarcas, y ningún hombre debe comprometerse de buena fe a creer y a pensar como lo exige su príncipe. Lo hemos dicho ya: nada es más libre que los sentimientos; podemos estar de acuerdo con las opiniones de otro exteriormente y de labios para afuera, pero nos es imposible estar de acuerdo también interiormente y contra nuestras propias luces, sin dejar de ser lo que somos», a saber: seres libres, como subraya Rousseau en El contrato social ${ }^{11}$, al que se remite también Romilly ${ }^{12}$.

Ante los derechos de la conciencia debe detenerse la intolerancia, tanto la religiosa como la civil. La libertad de conciencia es, pues, la base fundamental no sólo de la defensa de la tolerancia, sino también de la libertad religiosa y de la libertad de pensamiento.

Sobre la necesidad de admitir el hecho de la pluralidad o diversidad (de opiniones, de creencias), fundamentado en el derecho a la libertad de conciencia, ya se había pronunciado Locke en los términos siguientes: si existiera «una sola verdad, un solo camino hacia el cielo, ¿qué esperanza habría de que un número mayor de hombres fuese conducido a él, si no tuvieran ellos otras reglas que la religión de la corte y fueran obligados a dejar la luz de su propia razón, oponerse a los dictados de sus propias conciencias y resignarse ciegamente a la voluntad de los que gobiernan [...]?» ${ }^{13}$. Más explícito es Locke cuando, en su respuesta a la objeción según la cual la defensa de la tolerancia ampara o encubre reuniones o asambleas de Iglesias que alguna vez han sido el origen de sediciones. Considera el autor de la Carta sobre la Tolerancia que «estas acusaciones pronto cesarían si la ley de la tolerancia se impusiera de tal forma que todas las Iglesias se vieran obligadas a establecer la tolerancia como fundamento de su propia libertad y a enseñar que la libertad de conciencia es un derecho natural de cada hombre, que pertenece por igual a los que disienten y a ellos mismos, y que a nadie debiera obligársele en materia de religión, ni por la ley ni por la fuerza» ${ }^{14}$. Si todos los hombres tienen un derecho igual a la libertad de conciencia, no sólo queda desautorizada la práctica de la intolerancia en cualquiera de sus formas, sino que - lo que es una novedad en Europa - logra un fundamento filosófico tanto el hecho de la diversidad de opiniones como el de la pluralidad de formas de religión. Según Locke, «no es la diversidad de

11 J. J. Rousseau, «Du contrat social», en Oeuvres complètes, París, Gallimard (Pléiade), 1964 vol. III, Lib. I, cap. IV. [Sergio Sevilla (ed.), El contrato social, Madrid, Biblioteca Nueva, 2003].

12 J.-E. Romilly, art. «Tolérance», en Diderot et d'Alembert, Encyclopédie, edición de F. M. Ricci, op. cit., T. 45.

${ }_{13}$ J. Locke, «Carta sobre la Tolerancia», op. cit., p. 12; subrayo yo.

14 Ibid., p. 58; subrayo yo. 
opiniones (que no puede evitarse), sino la negativa a tolerar a aquellos que son de opinión diferente (negativa innecesaria) la que ha producido todos los conflictos y guerras que ha habido en el mundo cristiano a causa de la religión» ${ }^{15}$. Voltaire toma buena nota de este enunciado, que orienta en parte su investigación sobre la verdad histórica.

De lo que, en cambio, sólo debemos tomar una nota relativa es de la observación de H. Kamen según la cual Locke no ha sido original en su teoría de la tolerancia, porque se ha limitado a sistematizar los argumentos utilizados en las controversias religiosas del siglo anterior y, concretamente, en los debates que sobre la tolerancia tienen lugar en Inglaterra en la segunda mitad del siglo XVII ${ }^{16}$. En lo que se refiere a la libertad de conciencia, es cierto que, según observación del mismo Kamen, la libertad religiosa se estableció por un tiempo en Polonia en la época de la Reforma; concretamente el rey Segismundo Augusto responde a la petición de Roma de que elimine a los herejes con la siguiente declaración en la dieta de 1569: «Que nadie piense que utilizaré alguna vez la fuerza para llevar a alguien a la fe, o que oprimiré las conciencias.» Es importante evocar, además, la contribución de los socinianos a la defensa de la tolerancia y la libertad de conciencia. En 1605, esto es, al año siguiente de la muerte de Socino en Polonia, publicaron su gran confesión de fe conocida como el Catecismo de Rakow (Polonia). En el prefacio a la edición de 1665 se exponen los principios de una tolerancia positiva y completa y, por lo tanto, de la libertad religiosa: «Con la publicación de este Catecismo no intentamos imponer nada a nadie. Al exponer nuestra opinión no oprimimos a nadie. Que todos sean libres de expresar sus ideas en los asuntos religiosos, con tal de que también se nos permita a nosotros expresar nuestra opinión sobre las cosas divinas sin daño o recibir insultos... En lo que a nosotros respecta, todos somos hermanos y no se nos ha dado ningún poder ni autoridad sobre la conciencia de los demás» ${ }^{17}$. Pero, como admite Kamen, «la significación de Polonia como pionera de la tolerancia» ${ }^{18}$ no se puede comparar con la aportación inglesa. «Inglaterra fue el único país europeo que sobrepasó la defensa de los derechos de la conciencia para abogar por una justicia social e individual como parte de una libertad inalienable de la que la tolerancia religiosa no era más que un aspecto» ${ }^{19}$. En este sentido, la Carta sobre la Tolerancia es la expresión no sólo de la teoría de Locke, sino también de una argumentación madurada a lo largo de las controversias en torno a la libertad religiosa y civil, que dominan la vida inglesa en la segunda mitad del siglo XVII.

${ }^{15}$ Ibid., p. 65 .

${ }^{16}$ H. Kamen, The rice of Toleration, 1967; trad. esp. en Alianza, 1987, p. 223.

17 H. Kamen, Nacimiento y desarrollo de la tolerancia en la Europa moderna, Madrid, Alianza, 1987, pp. 107-108.

${ }_{18}$ Ibid., p. 111. Cf. J. Lecler, Histoire de la tolérance au siècle de la Réforme, París, 1955 (A. Michel, 1994).

${ }_{19}$ Ibid., p. 180; subrayo yo. 
Una breve mirada a la historia nos permite observar cómo la argumentación iniciada en dicho siglo resuena luego con fuerza en el siglo XVIII, cuando se trata de fundamentar la tolerancia en la libertad de conciencia. J. Harrington, por ejemplo, sostiene en Oceana (1656) que «es una contradicción que un gobierno defienda la libertad en general y reprima la de conciencia»; y en Aforismos políticos escribe: «Allí donde la libertad civil es completa, incluye la libertad de conciencia» ${ }^{20}$. Unos años antes el independiente escocés, H. Robinson, escribía en un opúsculo titulado Libertad de conciencia (Liberty of Conscience, 1643) contra los presbiterianos de Londres: «No hay término medio: o bien la libertad de conciencia nos permite mantener nuestras propias opiniones en materia de religión, o por el contrario estaremos obligados contra la conciencia, cuando los poderes civiles - que con seguridad no son más infalibles que los eclesiásticos- decidan aprobar una ley o instituir cualquier cosa» ${ }^{21}$. El obispo anglicano G. Brunet no sólo es un firme defensor de la tolerancia, sino uno de los pocos partidarios de la Iglesia anglicana de extender la tolerancia a los católicos; y ello por simple coherencia argumentativa: «Durante mucho tiempo he considerado la libertad de conciencia - escribe - como uno de los derechos de la naturaleza humana, anterior a la sociedad...; y la norma de nuestro Salvador - lo que queráis que os hagan hacedlo también vosotrosparecía ser un mandato expreso para todos los hombres» (Historia de mi época). Tal es la argumentación que luego se traduce en las Declaraciones de Derechos durante el siglo XVIm, concretamente en las del área de influencia inglesa como las de Virginia (1776) y Pennsilvania (1776). En el artículo 8 de la primera leemos: «La religión o el culto debido al Creador, y la manera de llevarlo a cabo, no deben ser dirigidos sino por medio de la razón y la persuasión, nunca por medio de la fuerza ni de la violencia, de donde se sigue que todo hombre debe gozar de la más perfecta libertad de conciencia; $[. .$.$] y que todos los ciudadanos tienen la obligación de practicar la tole-$ rancia cristiana.» La Declaración de Pennsilvania formula, además, el fundamento de la tolerancia al entender la libertad de conciencia como uno de los derechos naturales: «Todos los hombres tienen un derecho natural e inalienable a adorar al Dios omnipotente - se dice en el art. 2-, de la manera que le sea dictada por su conciencia y sus luces. [...] Ningún hombre que reconoce la existencia de un Dios debe ser privado de ningún derecho civil como ciudadano, ni de ninguna manera perseguido por motivo de sus sentimientos en materia de religión, o de la forma particular de su culto; [...] ningún poder del Estado [...] debe molestar ni perjudicar el derecho de la conciencia en el libre ejercicio del culto religioso» ${ }^{22}$. La Declaración de Derechos de Pennsilvania, que, como la de Virginia, reconoce otros dere-

${ }^{20}$ Cf. H. Kamen, op. cit., p. 165.

21 Ibid., pp. 166-167.

${ }^{22}$ A. Baecque (ed.), L'An 1 des Droits de l'homme, París, Presses du CNRS, 1988, p. 323. 
chos a la libertad o espacios de libertad en diferentes artículos, estaba inspirada directamente por el dirigente cuáquero William Penn, fundador de Pennsilvania, y uno de los defensores más coherentes de la tolerancia tanto en la práctica como en la teoría. En su obra La gran causa de la libertad de conciencia (1770), considerando que la libertad es un derecho natural como la propiedad, que la persecución es rechazable por ser contraria no sólo a la Escritura sino también los derechos naturales como el del libre uso de la razón, escribe: «Estamos convencidos de que ninguna ley temporal futura, contraria a nuestros derechos fundamentales (como sería la de ejercer violencia sobre la conciencia), puede invalidar aspectos tan esenciales de nuestro gobierno como la libertad y la propiedad inglesas» ${ }^{23}$.

Ahora bien, a diferencia de las Declaraciones de Virginia y Pennsilvania, en la Declaración de Derechos de $1789^{24}$ no encontramos el término libertad de conciencia ni el de tolerancia. ¿Significa, acaso, un paso a atrás con relación a las reivindicaciones americanas? ¿O equivale, al contrario, a una superación de la situación que demanda al menos tolerancia? Como es imposible analizar todos los aspectos de la cuestión en estas páginas, me limitaré a una breve anotación. Por una parte, hemos de observar que la Declaración del 89 (como también la del 93) no hace mención explícita de la libertad de conciencia, porque reconoce no sólo el derecho de todos a la libertad en general (art. 2), sino también espacios de libertad como la libertad individual (art.4), la libertad política, la libertad de pensamiento y expresión (art. 11), de la que forma parte la libertad de conciencia tal como se reconoce implícitamente en el artículo 10: «Nadie debe ser inquietado por sus opiniones, incluso religiosas, siempre y cuando su manifestación no perturbe el orden público establecido por la ley.» Más aún: el sentido de este enunciado está reforzado por otros anteriores en los que se reconoce a todos el libre acceso a los cargos públicos, sin más criterios de selección que la capacidad, la virtud y el talento, así como a la formación de la ley, dado que - éste es el argumento básico - todos los ciudadanos son iguales ante la ley (art.6). Por otra parte, cuando parecía que el problema estaba resuelto, al menos idealmente, se observa un nuevo problema surgido por el desplazamiento de la discriminación del plano religioso al plano sociológico y político. El concepto de ciudadano que se aduce como base de la igualdad política se interpreta en la práctica de un modo restrictivo $\mathrm{y}$, por lo tanto, discriminatorio. Se discrimina no sólo por razón de género, sino también por motivos económicos: entre los varones mayores de veintiún años, sólo aquellos que disponen de determinados ingresos económicos pueden ser elegidos para cargos públicos. Una tercera consideración nos llevaría a preguntarnos por las causas de la intolerancia política conocida como el «Terror», tan

${ }^{23}$ H. Kamen, op. cit., pp. 198-199.

24 A. Baecque (ed.), L'An 1 des Droits de l'homme, op. cit., pp. 198-200. A. Hamilton, J. Madinson y J. Jay, El federalista, traducción de G. R. Velasco, México, FCE, 1943. 
inhumana o más que la intolerancia religiosa del período de las guerras de religión. De las tres observaciones se infiere que el problema de la discriminación no está completamente resuelto ni siquiera cuando se diseña la sociedad democrática en textos fundacionales como los de la Revolución francesa. Se ha resuelto, al menos a nivel de principios, el problema de la intolerancia en materia de religión; pero se ha dejado un foco de contaminación discriminatoria por motivos económicos y de género.

\section{De la tolerancia religiosa a la tolerancia universal}

Con todo, no se puede analizar el debate sobre la tolerancia en la época moderna sin dirigir al menos una mirada a la posición de Voltaire. No cabe duda de que el Tratado sobre la Tolerancia (1763) está tan cercano teóricamente a las controversias del siglo XVII como a las Declaraciones de Derechos del siglo XVIII. Es, evidentemente, un canto a la tolerancia. En él reivindica la libertad de conciencia. Resalta la luz que para la humanidad supone este derecho natural, en contraste con la densa oscuridad que ha supuesto en la historia tanto el crimen de la noche de San Bartolomé como la brutal injusticia del caso Jean Calas ${ }^{25}$. Pero Voltaire apenas argumenta. Combate. Pone al descubierto los argumentos falaces de los apologistas de la revocación del Edicto de Nantes; contrasta puntos de vista, compara religiones, satiriza, investiga, aporta datos de una verdad histórica irrefutable: todas las religiones positivas han sido intolerantes, pero ninguna ha llevado el fanatismo hasta el grado de crueldad como lo ha hecho la religión católica. El defensor de la verdad jurídica de casos como los de Calas y Sirven prefiere dedicar su tiempo al conocimiento de la verdad histórica antes que perderlo en la discusión de la verdad teológica, «llena de sofismas y disputas incomprensibles» ${ }^{26}$. De ahí su importante tesis sobre la tolerancia universal ${ }^{27}$. Ahora bien, ¿en qué se funda dicha tesis? ¿Acaso sobre la base de la libertad de conciencia, como se propusieron entre otros Bayle y Bayle? ¿Qué ocurre si alguien asume que su conciencia le obliga a perseguir a los partidarios de otra forma de religión? ¿No debe, acaso, seguir sus dictados? Voltaire, como Bayle en sus últimas obras ${ }^{28}$, es consciente de que, si bien es preciso tener en cuenta los derechos de la conciencia, este criterio no puede tomarse como el único fundamento de la tolerancia. El criterio fundamental en favor de la tolerancia, tanto religiosa como universal, es la

${ }^{25}$ Voltaire, Tratado sobre la Tolerancia, edición de R. Rodríguez Aramayo, Madrid, Santillana, cap. III, p. 23.

${ }^{26}$ Ibid., cap. XXII, p. 78. Cf. A. V. Gentea, «Tolerancia y religión en la obra de Voltaire», Sistema, núm. 178, 2004, pp. 113-126.

${ }^{27}$ Ibid., cap. XXII.

${ }^{28}$ Cf. G. Mori, Bayle philosophe, París, Editions Champion, 1999, p. 304. 
razón (política) ${ }^{29}$. De ahí la pregunta que se hace Voltaire en el célebre Tratado: «Pero cómo! ¿Le será permitido a cada ciudadano no creer más que a su razón y pensar lo que esta razón, acertada o equivocada, le dictará? Es preciso, con tal de que no perturben el orden» ${ }^{30}$. Es evidente que en Voltaire y su siglo la razón potencia y limita, a la vez, la función y el espacio de la conciencia. Frente al dominio hegemónico de la verdad absoluta, la razón descubre y fundamenta el derecho a la libertad de conciencia, base de las libertades individuales. Pero, ante el posible abuso de los derechos de la conciencia - como ya observara Pierre Bayle, con evidente influencia en los pensadores ilustrados - , la razón le señala un límite en el espacio público acotado por la legítima ley, en cuyo marco la tolerancia de ideas, convicciones y creencias ha de ser universal.

Ahora bien, ¿qué significa tolerancia universal? Si nos atenemos al contexto de las polémicas religiosas, tolerancia universal refiere, en primer lugar, al reconocimiento mutuo de las diferentes Iglesias como posibles vías de salvación. Tal aceptación recíproca exige, desde una consideración negativa, la no exclusión de ninguna forma de religión - así como de la correspondiente Iglesia - del autorizado espacio público de acción; pero desde una perspectiva positiva, el reconocimiento de derechos en igualdad de condiciones dentro del mismo Estado, tal como lo reclamara Locke en su planteamiento utópico, es decir, como propuesta teórica de la igualdad ideal de las Iglesias, sin excepciones en la práctica. En segundo lugar, la tolerancia universal significa no sólo no obligar a ninguna persona a entrar, mediante el uso de la coacción o de la fuerza, en una determinada Iglesia, sino a reconocer y a respetar en todo momento en igualdad de condiciones los «derechos de la conciencia». No cabe duda de que, cuando Voltaire postula la tolerancia universal, conoce la argumentación de P. Bayle a favor de dicha tesis. En efecto, en su Commentaire philosophique a las palabras de san Lucas: «Oblígales a entrar» ${ }^{31}$, Bayle deconstruye el argumento de quienes, como san Agustín, justificaban no sólo la conversión forzada, sino también la persecución hasta en sus formas intolerantes de todo hereje o disidente, dado que el camino de salvación pasaba sólo por la «verdadera» Iglesia. Sostener que es justa la persecución si es llevada a cabo por la Iglesia verdadera, e injusta si la promueven las Iglesias heréticas, supone incurrir en una petición de principio, dado que se alega como prueba aquello que es preciso probar, a saber: que la Iglesia que tiene por legítima la persecución es la Iglesia verdadera. Ahora bien, reivindicando los derechos de la conciencia a

29 P. Bayle, «Commentaire philosophique», en J. M. Gros (ed.), De la tolérance, Presses Pocket, 1992; también: Oeuvres, Hildesheim, Olms, 1727/1965, t. II

30 Voltaire, op. cit., cap. XI, p. 46.

31 P. Bayle, «Commentaire philosophique sur ces paroles de Jésus-Christ: contrain-les d'entrer (1686)», en J. M. Gros (ed.), De la tolérance, Presses Pocket, 1992; también: Oeuvres, Hildesheim, Olms, 1727/1965, t. II. Cf. G. Mori, Bayle philosophe, París, Editions Champion, 1999; sobre todo el cap. 6, «Conscience et tolérance». 
la libre adhesión a lo que considera verdadera doctrina, y concediendo los mismos derechos a la conciencia errónea (sobre todo en el caso frecuente de la «ignorancia, invencible, de buena fe») que a la conciencia no errónea, se puede llegar a justificar para todas las religiones el derecho universal a perseguirse mutuamente sin restricciones. Pero como, si se concede tal derecho, la intolerancia universal genera un proceso ininterrumpido de intolerancia y de exterminio recíproco, el argumento llevado al extremo conduce a su formulación positiva, a saber: a la tesis de la tolerancia universal, fundada en el igual derecho de la conciencia a la libre adhesión a la fe revelada y a la forma concreta de llevarla a la práctica. En tal reconocimiento recíproco tiene su base la nueva conciencia religiosa, moderna, de la sociedad plural que emerge con la Reforma y las guerras de religión, tal como lo ha admitido, entre otros, John Rawls ${ }^{32}$. La tolerancia universal o recíproca vinculada a la libertad de conciencia bajo la forma de libertad de religión, sobre la base del pluralismo, constituye, por otra parte, «un modelo para la estructura mental necesaria en las sociedades multiculturales», como - sobre la base de la observación de Rawls, a quien cita - reconoce Habermas ${ }^{33}$.

¿Alumbró el Siglo de las Luces la sociedad moderna multicultural? La tesis de la tolerancia universal defendida por Voltaire, y sugerida - con restricciones - por los defensores de la tolerancia en el siglo XVIII, no se entiende sino fundamentada sobre las siguientes condiciones teórico-prácticas. En primer lugar, el desplazamiento de la búsqueda de un fundamento para la tolerancia del ámbito estrictamente religioso hacia el espacio público de lo político, dado el carácter irracional de la religión. En segundo lugar, la distinción y separación de los fines y, por lo tanto, de las funciones de la Iglesia de los del Estado. Spinoza, Bayle y Locke ya lo habían planteado abiertamente, dando pie a la reivindicación en igual sentido de Rousseau y Romilly, entre otros. En tercer lugar, la neutralidad del Estado: la apuesta por la tolerancia era incompatible con la costumbre según la cual cada rey podía imponer su religión a sus súbditos, habiéndola adoptado antes como religión de Estado. Más aún: la distinción lockeana entre la sociedad política y la comunidad religiosa no sólo contradice el viejo lema: «una fe, una ley, un rey», establecido por la paz (religiosa) de Augsburgo, en 1555, sino que destruye la esencia misma del origen divino del poder absoluto. Pero yendo más allá de Locke, en quien subsiste todavía la idea de un Estado cristiano, Romilly escribe que «la salvación de las almas no ha sido confiada al magistrado ni por la ley revelada, ni por la ley natural, ni por el derecho políti-

${ }^{32}$ La Reforma, observa Rawls, «fragmentó la unidad religiosa de la Edad Media y condujo al pluralismo religioso, con todas sus consecuencias para los siglos posteriores. Lo que a su vez propició pluralismos de otros tipos, que acabaron convirtiéndose en un rasgo permanente de la cultura hacia finales del siglo XviI» (El liberalismo político, traducción de A. Domènech, Barcelona, Crítica, 1996, p. 18).

${ }^{33}$ J. Habermas, «De la tolerancia religiosa a los derechos culturales», Claves de la Razón Práctica, núm. 129, enero-febrero de 2003, p. 12. 
co» ${ }^{34}$. En cuarto lugar, por lo tanto, la subordinación de la jurisdicción eclesiástica - de todas las Iglesias - a la jurisdicción del Estado. El ius circa sacra que corresponde al Estado no es un derecho de persecución de algunos súbditos a causa de sus creencias, sino un deber de protección de todos los ciudadanos, por encima de sus creencias, y siempre que éstas no produzcan actitudes intolerantes ni perturben el orden o la paz social. En este aspecto coinciden todos los defensores de la tolerancia, desde Spinoza a Voltaire. Romilly formula del siguiente modo la subordinación de lo espiritual a lo temporal, esto es, lo que se conoce como el principio de laicidad moderna: «Que el Estado sea uno, que el sacerdote sea ante todo un ciudadano; [...] que su autoridad puramente espiritual se limite a instruir, a exhortar, a predicar la virtud; que aprenda de su divino maestro que su reino no es de este mundo» ${ }^{35}$. Finalmente, para que sea efectiva, la autoridad neutral del Estado no sólo debe admitir en su territorio la multiplicidad de confesiones religiosas, sino que también debe reconocerles los mismos derechos, tratarlas con igual respeto y garantizarles igual protección; pero también ha de exigir, al mismo tiempo, que las diferentes confesiones/Iglesias reconozcan y acepten mutuamente sus respectivos derechos.

Sólo sobre estas bases la tolerancia religiosa - objeto de duras polémicas en la época moderna -, con fundamento en la razón política, puede constituir una referencia histórica modélica para la estructura mental indispensable en las sociedades multiculturales, incluyendo en ellas a la nueva Europa. «La coexistencia en igualdad de derechos de diferentes formas de vida no debe conducir a la segmentación - concluyo con Habermas - . Por el contrario, requiere la integración de los ciudadanos - y el reconocimiento recíproco de sus pertenencias culturales - en el marco de una cultura política compartida» ${ }^{36}$. Ello requiere, sin duda, tanto la idea como la pequeña virtud indispensable para la vida del Estado democrático ${ }^{37}$ : la tolerancia universal.

\footnotetext{
34 J.-E. Romilly, art. «Tolérance», en Encyclopédie, edición de F. M. Ricci, op. cit. (tt. 44-45)

35 J.-E. Romilly, art. «Tolérance», op. cit. (t. 45); el segundo subrayado es mío.

36 J. Habermas, art. cit., p. 12.

37 1. Fetscher, La tolerancia. Una pequeña virtud imprescindible para la democracia. Panorama histórico y problemas actuales, traducción de Nélida Machain, Barcelona, Gedisa, 1994.
} 